\title{
Cystic Echinococcosis in Northern Cyprus: A Literature Review
}

\author{
Emrah Ruh' (1), Ayșegül Taylan Özkan,2 (1) \\ 'Department of Medical Microbiology and Clinical Microbiology, Near East University School of Medicine, Nicosia, Northern Cyprus \\ ${ }^{2}$ Department of Medical Microbiology, Hitit University School of Medicine, Çorum, Turkey
}

ORCID IDs of the authors: E.R. 0000-0003-474I-9450; A.T.Ö. 0000-000I-842I-3625.

Cite this article as: Ruh E, Taylan Özkan A. Cystic Echinococcosis in Northern Cyprus: A Literature Review. Cyprus J Med Sci 2018; 3(3): 193-6.

\begin{abstract}
Cystic echinococcosis is a zoonotic disease caused by the larval stages of Echinococcus granulosus sensu lato (s.l.). The life cycle of the parasite consists of dogs and other canids as the definitive hosts and ungulates, such as sheep and goats, as the intermediate hosts. Humans are accidental intermediate hosts in the life cycle of the parasite. The island of Cyprus is located in the eastern part of the Mediterranean region where echinococcosis is endemic. The disease was common in the island until the 1970s. In Southern Cyprus, two control programs for echinococcosis were implemented; the first one was initiated in 197/ and continued until 1985, and the second one was introduced in 1993 and implemented for 5 years. The control programs resulted in a decrease of the prevalence in both dogs and livestock. In Northern Cyprus, a control program was implemented between 1997 and 2005 that also resulted in a decrease of the disease rates in definitive and intermediate hosts. However, termination of the program led to an increase in the prevalence. Recent data suggest that sporadic cases of echinococcosis still exist; therefore, control programs should be continued in order to prevent the disease in Northern Cyprus.
\end{abstract}

Keywords: Cystic echinococcosis, Echinococcus granulosus, prevalence, Northern Cyprus

\section{INTRODUCTION}

Echinococcosis, also referred to as hydatid disease, is a zoonosis developed by the larval stages of Echinococcus, which is a cestode parasite (I). It is one of the neglected tropical diseases and also listed among the priority neglected zoonotic diseases defined by the World Health Organization (2).

Different clinical forms of echinococcosis in humans include cystic echinococcosis (CE), which is caused by Echinococcus granulosus sensu lato (s.l.) (3); alveolar echinococcosis ( $A E$ ), developed by Echinococcus multilocularis; and polycystic echinococcosis, caused by Echinococcus vogeliand Echinococcus oligarthrus (4). CE and AE are the most common clinical forms of the disease, and they cause health and financial problems especially in low-income countries (5). The highest rates of E. granulosus are documented from Eurasia, Africa, Australia, and South America (6). E. multilocularis is limited to the Northern Hemisphere, whereas it is widespread in this region (7). Polycystic echinococcosis is restricted to Central and South America and reported rarely in humans (I).

Cystic echinococcosis has a worldwide distribution and is endemic in areas including Peru, Chile, Argentina, Uruguay, Southern Brazil, Mediterranean region, Central Asia, Western China, and East Africa. It is a particular concern in poor rural regions where livestock and dogs are typically present and maintain transmission of the infecting parasite (4).

Cystic echinococcosis has significant impact on human health (6). It is estimated that >I million people are infected globally, with >I million disability-adjusted life-years lost each year. Furthermore, the economic burden of human CE is estimated to be $>\$ 750$ million, whereas the estimated cost of the infection in livestock was reported to be $>\$ 2$ billion per year globally (8).

The Mediterranean region is one of the areas in which the highest rates of zoonotic diseases are recorded (9). The annual incidence rate of human CE was reported to be 4-8/100,000 in this region (I0). Furthermore, CE was indicated as one of the five most common zoonotic diseases in the Mediterranean region (9).

This study was presented at the $9^{\text {th }}$ National and $2^{\text {nd }}$ International Congress of Hydatidology. November I5-17, 2018. Nicosia, Cyprus. 
Cyprus is a Mediterranean island where CE was commonly encountered in the past. The disease was detected not only in animals but also in humans. In order to prevent the further spread of CE in the island, control programs were implemented, and these campaigns resulted in substantial reductions of the prevalences in both dogs and livestock (II, 12). In Northern Cyprus, a control program for echinococcosis was also implemented; however, after termination of the program, the disease re-emerged in the country (I3).

In this review, first, the transmission of E. granulosus and the clinical manifestations of CE are summarized. Then, the presence of CE in Cyprus is discussed with a focus on Northern Cyprus. In addition, the impacts of the control programs on animal hosts and the reported human CE cases are reviewed.

\section{CE and the Life Cycle of E. granulosus}

CE is caused by the larval stages of E. granulosus sensu lato (s.l.). This complex includes five species: E. granulosus sensu stricto (s.s.) (genotypes Gl-G3), Echinococcus equinus (G4), Echinococcus ortleppi(G5), Elodea canadensis (G6, G7, G8, and GI0), and Echinococcus felidis (3). Among these, E. granulosus sensu stricto (s.s.) is considered to be the most important human pathogen (14).

In the life cycle of the parasite, dogs and other canids are the definitive hosts, whereas ungulates (e.g., sheep and goats) are the intermediate hosts. Humans are accidental intermediate hosts for the parasite (I).

Dogs have an easy access to the viscera of livestock particularly in rural regions (I5). For this reason, the definitive hosts can also ingest the offal that contains the hydatid cysts. In this case, the adult form of the parasite develops in the small intestine of a canine. The eggs are passed in the stool of an infected animal. After ingestion of the eggs by the intermediate hosts, the larva (oncosphere) hatches from the egg, penetrates the intestinal mucosa, reaches the bloodstream, and migrates to the liver, lungs, and other internal organs. Here, the oncosphere develops into the metacestode (hydatid cyst) (I).

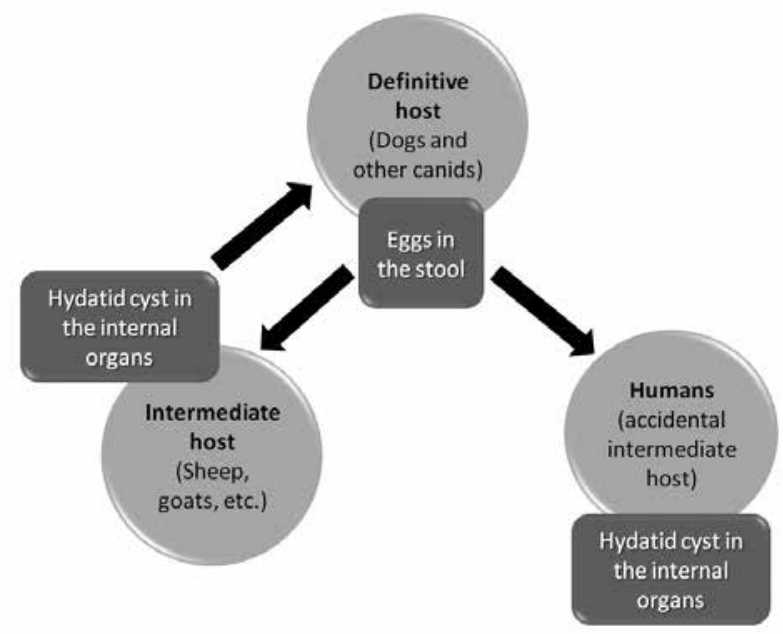

FIGURE I. Transmission of CE between the definitive and intermediate hosts
Within the cyst, brood capsules and protoscolices bud from the germinal layer, and daughter cysts are generally formed. When the organs of the intermediate hosts that contain the cyst are ingested by the definitive hosts, the life cycle of the parasite can start again. In the definitive hosts, the protoscolices evaginate, attach to the intestinal mucosa, and develop into the adult form in 30-80 days ( 1 ).

Humans can be infected via the fecal-oral route when dogs pass E. granulosus eggs in their stool. Humans can ingest the parasite eggs directly through close contact with dogs or indirectly by consuming contaminated water and uncooked meat (I5).

A number of factors can facilitate the transmission of the parasite between animals and humans. Potential risk factors that are related with CE include free dog roaming, feeding dogs with viscera, dog ownership, slaughtering at home, insufficiently controlled slaughterhouses, living in rural regions, and low income (16).

Figure I summarizes the transmission of CE between the definitive and intermediate hosts.

\section{Clinical Manifestations of CE}

Cystic echinococcosis most frequently involves the liver. The second most commonly affected organ is the lung. Apart from these, the cyst can also reach other organs and structures in the body (4).

Generally, the cyst grows slowly; therefore, CE is mostly asymptomatic for a long time. Usually, primary infections comprise a single cyst; however, nearly $20 \%-40 \%$ of the individuals can have more than one cyst. Enlargement of the liver, right upper abdominal pain, nausea, and vomiting are the signs and symptoms of liver hydatidosis. Leakage or rupture of the cyst can result in anaphylaxis (I).

Secondary CE can develop as a result of cyst rupture in the peritoneal cavity, and the protoscolices and/or small cysts can form larger cysts. The growing cysts can lead to obstruction in the portal vein or bile duct, which may cause segmental or lobar atrophy of the liver. Other complications include cyst rupture in the biliary tree and secondary cholangitis, obstruction of the bile duct by daughter cysts, and development of fistula (I).

Since the infection can be asymptomatic for a long period, the clinical diagnosis of CE is generally difficult. Therefore, physical examination, radiological techniques, and serological tests are performed for the diagnosis of $\mathrm{CE}(6,17)$.

\section{The Island of Cyprus and its Importance for Echinococcosis}

Cyprus is situated in the east of the Mediterranean region, between $34^{\circ} 33^{\prime}-35^{\circ} 42^{\prime}$ northern latitudes and $32^{\circ} 16^{\prime}-34^{\circ} 36^{\prime}$ eastern longitudes (18). In the island, agriculture is an important source of income, where crop and livestock production is common (II). Echinococcosis was commonly encountered in Cyprus until the 1970s. The intermediate hosts were seriously affected by the parasite, and also the disease was an important public health issue. The annual surgical incidence rate was recorded as 12.9/100,000, which was one of the highest proportions recorded for echinococcosis worldwide (12). The high prevalence of infec- 
tion was attributed to several factors including the abundance of stray dogs, improper slaughter of animals, inappropriate disposal of the infected offal, poor awareness of the parasite's life cycle in the community, and climate, which is favorable for the survival and dispersal of the parasite eggs (19).

\section{Implementation of Two Echinococcosis Control Programs in Southern Cyprus}

In 1971, the first control program for echinococcosis was initiated in the island. The program continued in Southern Cyprus (Greek Cypriot community) until 1985; however, it was abandoned in Northern Cyprus (Turkish Cypriot community) after 1974 (12). The control program achieved successful results in both dogs and livestock. During the implementation of the program, the infection rates were reduced from $14.1 \%$ to $0 \%$ in dogs, from $50 \%$ $60 \%$ to $0.11 \%$ in sheep, from $14.5 \%$ to $0.01 \%$ in goats, from $18.6 \%$ to $0.04 \%$ in pigs, and from $38.9 \%$ to $0.87 \%$ in cattle (II). By the year 1985, echinococcosis was considered to have been eradicated in both definitive and intermediate hosts; therefore, the program was terminated. After 1985, sporadic cases were detected in livestock, and transmission of echinococcosis continued between dogs and livestock. Eventually in 1993, the second control program for echinococcosis was initiated in Southern Cyprus (12) and implemented for 5 years (II). The infection was detected in 16 dogs in 1993, but this number was reduced to zero by 1997. The infection rates declined from $0.088 \%$ to $0.011 \%$ in cattle, from $0.033 \%$ to $0.007 \%$ in sheep, and from $0.0112 \%$ to $0.0006 \%$ in goats between 1994 and 1999 (12).

\section{Northern Cyprus and Implementation of the Echinococcosis Con- trol Program}

The area of Northern Cyprus covers approximately one-third of the island. The population of the country was reported to be 286,257 , whereas the numbers of people living in urban and rural regions were documented as 197,484 and 88,773 , respectively, according to the 2011 census (20). The economy of Northern Cyprus is based primarily on the public sector, trade, tourism, and education (21). The main economic activities include agriculture and animal husbandry in the rural areas of the country (22).

In 2010, the numbers of sheep, goats, and cattle were documented to be $186,424,54,440$, and 47,972 , respectively, in Northern Cyprus. Importantly, the presence of inadequately supervised slaughterhouses and slaughtering of small ruminants outside the abattoirs were also reported. Moreover, the number of dogs was estimated to be 15,000 , whereas the number of registered dogs was noted to be 13,500 . The number of stray dogs was shown to be increasing (I3). Taken together, these suggest that the possible risk factors for CE are present in Northern Cyprus (16).

The echinococcosis control program that was initiated in 1971 did not continue in Northern Cyprus (Turkish community) after 1974, and the disease was detected in both humans and livestock (12). A study conducted in Northern Cyprus documented the prevalence rates of echinococcosis in sheep and cattle processed in slaughterhouses of Famagusta and Nicosia between 1993 and 1998. The rates of echinococcosis were reported to be $71.1 \%$ in sheep and $46 \%$ in cattle in the slaughterhouse of Famagusta. The prevalences in the slaughterhouse of Nicosia were reported to be $30.33 \%$ and $13.16 \%$ in sheep and cattle, respectively (23).
Owing to the high prevalence rates, a control program for echinococcosis was implemented between 1997 and 2005 in Northern Cyprus (I3). During the period of 1997 and 2002, the rate of CE declined from $0.9 \%$ to $0.0 \%$ in sheep $<2$ years, whereas this percentage was reduced from $48 \%$ to $4 \%$ in sheep $>2$ years. The prevalence of the infection also declined in cattle and goats. The rate of CE in dogs decreased from $1.95 \%$ to $0.0 \%$ between 1998 and 2004. Termination of the control program resulted in an increase in the prevalences, and finally, CE re-emerged in Northern Cyprus (13). In 20I0, the prevalences of CE were reported to be $14.9 \%, 5.57 \%$, and $3.16 \%$ in sheep, goats, and cattle, respectively. Furthermore, the rate of E. granulosus infection in dogs was estimated to be $5 \%$ (I3).

\section{Human Echinococcosis Cases in Cyprus}

Apart from the cases in dogs and livestock, disease in humans was also demonstrated in the island. According to data collected from government hospitals, 160 surgical operations of CE were performed between 1980 and 1998 in Southern Cyprus. The operations in the private clinics were excluded in the data; therefore, the actual number of cases was noted to be $>160$. Among individuals $<20$ years old, no case of CE was detected in Southern Cyprus; however, three cases were documented in this age group from Northern Cyprus. Cases from Southern Cyprus primarily consisted of latent infections, and as a result of the control program, the transmission cycle between dogs and humans was blocked (II).

A report from Cyprus demonstrated four cases of isolated cardiac echinococcosis in the 12 years prior to 2000 (24). After this period, sporadic cases appear to have occurred in the island. Data obtained from the European Centre for Disease Prevention and Control (ECDC) suggest that echinococcosis has been detected at very low levels in Cyprus. A total of four (two in 2011 and two in 2015) confirmed echinococcosis cases were reported from Cyprus between 2011 and 2015. The first three countries that reported the highest number of cases in 2015 were Bulgaria $(n=3 \mid 3)$, Germany $(n=145)$, and Spain $(n=83)$ according to the ECDC report (25).

In Northern Cyprus, 80 surgical cases were documented between 1990 and 1996. The annual incidence rate was recorded as $5.7 / 100,000$. Together with the number of individuals operated abroad, the estimated rate for 1995 was noted to be a minimum of $25 / 100,000$. As the proportions were determined according to data obtained from surgical operations, the number of actual cases was suggested to be higher (I3). Echinococcosis was detected in the radiological examination of $43(1.73 \%)$ out of 2480 individuals between 1996 and 1999 (23). In 2010, the surgical prevalence of human CE was documented to be $4 / 100,000$ (I3).

More recently, a preliminary investigation in Northern Cyprus included 688 individuals to evaluate the presence of human echinococcosis by serological tests. Seven (1.0\%) out of 688 samples were found to be positive by Western blot. Four out of seven individuals were detected to be positive for E. granulosus, whereas the remaining three were positive for E. multilocularis (26).

\section{CONCLUSION}

In the island of Cyprus, sporadic cases of echinococcosis appear to occur at low levels. Implementation of control programs 
in Southern Cyprus achieved successful results in both definitive and intermediate hosts. The control program in Northern $\mathrm{Cy}$ prus also resulted in a decrease of the CE rates. However, the prevalences increased in Northern Cyprus after termination of the program.

Previous and recent findings on echinococcosis suggest that the disease cannot be ignored in Northern Cyprus. The possible transmission of $E$. granulosus can be prevented by control measures, such as management of stray dog population, deworming of dogs with praziquantel, administration of the EG95 vaccine to sheep and goats, maintaining hygiene at slaughterhouses, and raising public awareness by education programs, particularly in the rural settings. In addition, more studies should be conducted to evaluate the presence of $\mathrm{CE}$ in humans, dogs, and livestock in Northern Cyprus.

Peer-review: Externally peer-reviewed.

Author contributions: Concept - E.R., A.T.Ö.; Design - E.R.; Supervision A.T.Ö.; Analysis and/or Interpretation - E.R., A.T.Ö.; Literature Search E.R., A.T.Ö; Writing - E.R.; Critical Reviews - A.T.Ö.

Conflict of Interest: The authors have no conflicts of interest to declare.

Financial Disclosure: The authors declared that this study has received no financial support.

\section{REFERENCES}

I. Nunnari G, Pinzone MR, Gruttadauria S, Celesia BM, Madeddu G, Malaguarnera $G$, et al. Hepatic echinococcosis: clinical and therapeutic aspects. World J Gastroenterol 2012; 18: 1448-58. [CrossRef]

2. Meeting of the WHO Informal Working Group on Echinococcosis (WHO-IWGE), Geneva, Switzerland, 15-16 December 2016. Geneva, Switzerland: World Health Organization; 2017 (WHO/HTM/NTD/ NZD/2017.0I)

3. Orsten S, Boufana B, Ciftci T, Akinci D, Karaagaoglu E, Ozkuyumcu C, et al. Human cystic echinococcosis in Turkey: a preliminary study on DNA polymorphisms of hydatid cysts removed from confirmed patients. Parasitol Res 2018; I17: 1257-63. [CrossRef]

4. Agudelo Higuita NI, Brunetti E, McCloskey C. Cystic Echinococcosis. J Clin Microbiol 2016; 54: 518-23. [CrossRef]

5. Otero-Abad B, Torgerson PR. A systematic review of the epidemiology of echinococcosis in domestic and wild animals. PLoS Negl Trop Dis 2013; 7: e2249. [CrossRef]

6. Rinaldi F, Brunetti E, Neumayr A, Maestri M, Goblirsch S, Tamarozzi F. Cystic echinococcosis of the liver: A primer for hepatologists. World J Hepatol 2014; 6: 293-305. [CrossRef]

7. Torgerson PR, Keller K, Magnotta M, Ragland N. The global burden of alveolar echinococcosis. PLoS Negl Trop Dis 2010; 4: e722. [CrossRef]

8. Tamarozzi F, Akhan O, Cretu CM, Vutova K, Akinci D, Chipeva R, et al. Prevalence of abdominal cystic echinococcosis in rural Bulgaria, Romania, and Turkey: a cross-sectional, ultrasound-based, popu- lation study from the HERACLES project. Lancet Infect Dis 2018; I8: 769-78. [CrossRef]

9. Dakkak A. Echinococcosis/hydatidosis: a severe threat in Mediterranean countries. Vet Parasitol 20I0; 174: 2-II. [CrossRef]

10. Grosso G, Gruttadauria S, Biondi A, Marventano S, Mistretta A. Worldwide epidemiology of liver hydatidosis including the Mediterranean area. World J Gastroenterol 2012; 18: 1425-37. [CrossRef]

II. Economides P. Control of zoonoses in Cyprus. Rev Sci Tech 2000; 19 725-34. [CrossRef]

12. Economides P, Christofi G. Evaluation of control programmes for echinococcosis/hydatidosis in Cyprus. Rev Sci Tech 2000; 19: 78492. [CrossRef]

13. Vural G. Turkish Cypriot community. Technical Assistance on Animal Husbandry in the Northern Part of Cyprus. Mission Report by Short-Term Expert. 2010.

14. Ito A, Nakao M, Lavikainen A, Hoberg E. Cystic echinococcosis: Future perspectives of molecular epidemiology. Acta Trop 2017; 165 3-9. [CrossRef]

15. Moro P, Schantz PM. Echinococcosis: a review. Int J Infect Dis 2009; 13: 125-33. [CrossRef]

16. Possenti A, Manzano-Román R, Sánchez-Ovejero C, Boufana B, La Torre G, Siles-Lucas M, et al. Potential Risk Factors Associated with Human Cystic Echinococcosis: Systematic Review and Meta-analysis. PLoS Negl Trop Dis 2016; 10: e0005II4. [CrossRef]

17. Güreser AS, Özcan O, Özünel L, Boyacıoğlu Zi, Taylan Özkan A. Evaluation of the radiological, biochemical and serological parameters of patients prediagnosed as cystic echinococcosis in Çorum, Turkey. Mikrobiyol Bul 2015; 49: 231-9. [CrossRef]

18. Demir S, Gocmen B, Ozbel Y. Faunistic study of sandflies in Northern Cyprus. North-West J Zool 2010; 6: 149-61.

19. Economides P, Christofi G, Gemmell MA. Control of Echinococcus granulosus in Cyprus and comparison with other island models. Vet Parasitol 1998; 79: 151-63. [CrossRef]

20. Country's physical plan - Section II. Nicosia: Town Planning Department, Ministry of Interior, Turkish Republic of Northern Cyprus 2014.

21. Seyer A, Karasartova D, Ruh E, Güreser AS, Turgal E, Imir T, et al Epidemiology and Prevalence of Blastocystis spp. in North Cyprus. Am J Trop Med Hyg 2017; 96: I164-70. [CrossRef]

22. Country's physical plan - Section IV. Nicosia: Town Planning Department, Ministry of Interior, Turkish Republic of Northern Cyprus $20 \mid 4$.

23. İnan $M$, Dağlı O, Soyuöz Ș, Zorlu $D$, Akalın A, Eralp S, et al. KKTC'de Insan ve Hayvanlarda Görülen Ekinokok Hastalığı ve Eradikasyon Programı Önerisi. [Article in Turkish]. Cyprus Turkish Medical Journal 2000; I: 14-9.

24. Moutiris JA, Mavrommatis P, Zambartas C, Henein M. Isolated cardiac echinococcosis in Cyprus. Int J Cardiol 2000; 75: 99-10I. [CrossRef]

25. European Centre for Disease Prevention and Control. Echinococcosis. In: ECDC. Annual epidemiological report for 2015. Stockholm: ECDC; 2017. Available from: URL: https://ecdc.europa.eu/en/publications-data/echinococcosis-annual-epidemiological-report-2015

26. Ruh E, Güreser AS, Karasartova D, Bostancı A, Taylan Özkan A. Echinococcosis in Northern Cyprus: Current Human Cases. Oral Presentation no: SBII. $8^{\text {th }}$ National and Ist International Congress of Hydatidology. Corum, Turkey. 2017. 